\title{
A DSM-Based Validation Tool for Leveraged Optimization of Internal Control
}

\author{
Denise Hunter ${ }^{1}$, Carl Dister ${ }^{2}$, Bill Klinger ${ }^{3}$, Tyson Browning ${ }^{4}$ \\ ${ }^{1}$ Director, Corporate Risk Management, Corporate Compliance \& Ethics \\ North American Electric Reliability Corporation \\ ${ }^{2}$ Chief Innovation Manager, ReliabilityFirst Corporation \\ ${ }^{3}$ Principal Consulting Engineer, Klinger Engineering Services \\ ${ }^{4} \mathrm{Ph} . \mathrm{D}$., Professor of Operations Management, \\ Neeley School of Business, Texas Christian University
}

\begin{abstract}
When striving to ethically balance opportunity and risk, organizations can become overwhelmed by the number of interrelated processes that must be understood and managed. A DSM-based validation tool — readily built in an ordinary spreadsheet file - can systematically guide an organization's leveraged application of resources to optimize the effectiveness of an internal control system.
\end{abstract}

Keywords: risk management, internal control, system of systems, systems thinking, auditing, effectiveness assessment.

\section{Introduction: Internal Control}

One type of organizational risk management is internal control (IC): "a process ... designed to provide reasonable assurance regarding the achievement of objectives relating to operations, reporting, and compliance" (COSO 2013b, 3). Systems engineers apply ICs to improve the reliability of products and services (INCOSE 2015). The accounting and auditing professions implement ICs to mitigate corporate risk. When well executed, a systematic IC program can detect (and even prevent) fraud and waste.

Depending on the needs of a given organization, various IC program models may prove useful, as tabulated in a roundup of maturity grids (Maier et al. 2011).

This paper presents a real-world case from the auditing domain that illustrates what can go wrong when an IC program is poorly deployed. We use the real-world case to demonstrate our novel methodology and DSM tool.

\section{Real-World Case}

Denise Hunter (the first author) intentionally relates the following story in the first person to convey a vivid, accountable sense of her firsthand experience.

\subsection{A Story of Internal Control Deficiencies}

In 2006, as Lead Auditor for a multinational, Fortune 100 company, I led a team of auditors in examining a manufacturing plant and four associated warehouses. At each facility, "micro teams" were charged with performing periodic, local audits. Prior to auditing, the 
warehouse reports showed operations running smoothly. However, the initial review by my auditing team discovered a discrepancy in inventory: 36,000 boxes of product had been incorrectly recorded. My role then shifted to that of a Forensic Auditor, investigating the problem.

At the time, corporate management was aware of a glitch in the company's inventory software, which did not accurately track discontinued-product inventory. Once production of a Stock Keeping Unit (SKU) Code ceased, that SKU's inventory should have been gradually depleted, with no further additions of newly-manufactured product. Unfortunately, a software loophole allowed inventory counts to be arbitrarily increased, despite the cessation of a given SKU's production.

To mitigate the software flaw, management added four new ICs:

- The Inventory Manager and the Warehouse Manager were required to check inventory against Discontinued SKU Lists provided to them.

- For each and every SKU having at least 1,000 boxes in stock:

$\circ$ the Warehouse Manager (who supervised the Inventory Manager) was required to reconcile the Inventory System Figures to the supporting Count Sheets, and

$\circ$ the Regional Director was required to conduct a random sampling of SKUs, examining $10 \%$ of the stock on hand.

- Three people (instead of two) were required to independently verify the existence of product inventory, making sure the pertinent Count Sheets matched.

We validated that the Count Sheets accurately reflected the current warehouse inventory, yet I suspected that someone might have found a way to exploit the software glitch. We discovered that the new ICs had failed because the Warehouse Manager did not perform reconciliations, the Regional Director did not conduct samplings, and no one checked inventory against the Discontinued SKU Lists.

Moreover, we determined that the Inventory Manager had been manipulating his inventory reports for years. At least 100,000 boxes of product were affected. Nobody suspected the man of wrongdoing because he had a reputation as an ever-helpful, trustworthy person. $\mathrm{He}$ was The Golden Child who always "made budget"-despite the improbability of consistently achieving such ideal results. His stock figures were never more than 100 boxes "off."

I went in search of the Inventory Manager, who had stopped reporting for work and then e-mailed his resignation notice to the company. In a confidential interview, the Inventory Manager admitted that he was falsifying reports. He believed the impact of his actions was negligible. He had no idea that, over time, $\$ 500,000$ worth of products had been wrongly tracked. In fact, those products never existed. The manager simply forced his reported inventory figures to match his budget — confident that no one was checking. He maintained that unrelenting corporate pressure to perform to ever-higher expectations was the root cause of his deceptive behavior. In a tough economy, he feared losing his job, should his performance be deemed less than excellent.In the aftermath of the scandal, the Warehouse Manager was demoted to a Warehouse Worker, the Regional Director's activity was scrutinized via a Performance Plan, and the Primary Compliance Contact was fired. Further, the affected warehouse was placed on a revolving six-month Oversight Plan. [End of first-person testimony.] 


\subsection{Value of the COSO Internal Control Model}

How did the first author manage to sense something amiss at the warehouse and then rapidly identify the nature, extent, and cause of the fraud? Beyond her base of professional knowledge and experience, she systematically applied the COSO "Integrated Framework" (developed by the Committee of Sponsoring Organizations of the Treadway Commission, and first published in 1992).

The Integrated Framework (COSO 2013b, 4-5) consists of five Components:

- Control Environment (Organizational Culture)

- Risk Assessment

- Control Activities

- Information and Communication

- Monitoring Activities

Auditors may overlook or misunderstand the vital importance of all five components working in concert. A Critical Systems Thinking approach (Jackson 2019) can help assure that an IC system raises a red flag whenever a control is "broken"-most commonly due to changes in personnel, technology, organizational structure, or operations.

\subsection{Forensic Analysis}

In the first author's story, each and every COSO Integrated Framework Component was less than ideally implemented, as the following evidence shows:

- Multiple employees working in the Control Environment did not comprehend the importance of supporting the IC program, with integrity. The Inventory Manager, the Warehouse Manager, the Regional Director, and the Primary Compliance Contact all viewed IC as a useless "corporate mandate." They failed to take their responsibilities seriously because the culture of the organization tolerated such laxity.

- The Risk Assessment process did not identify the need to enforce Segregation of Duties, which would have prevented inventory reporting solely by a single individual, unchecked.

- Control Activities failed in three areas:

$\circ$ Validations were not performed.

○ Human Resources was oblivious to the Inventory Manager never "missing inventory."

○ There was no red flag for Budget Figures that were always incredulously "on target."

- Information and Communication became untrustworthy. The Regional Director blindly relied upon the Inventory Manager's (falsified) reports for forecasting and planning. While the Regional Director had four warehouses of similar size under his control, he did not question the Inventory Manager's figures, which were disproportionate in comparison to those of the other three warehouses. Common sense could have helped here.

- Monitoring Activities broke down. Finance Controls could have evoked concern when Sales Figures and Order Figures did not equate to Inventory Figures. Compliance Oversight activities should have caught the discrepancies.

Had the IC system functioned as a coherent whole, the Inventory Manager's manipulations 
might have been altogether deterred. At the least, his deception would have been exposed much sooner.

\subsection{Corrective Actions}

To remedy the IC program failures, the corporation made a strong push, clarifying the importance of ICs. Management worked to improve communication among staff and workers. Refresher training was conducted at each manufacturing plant and every warehouse. Overall, these corrective initiatives cost an estimated $\$ 325,000$.

\section{The Challenge}

ICs typically direct the application of organizational resources, monitor operations, and measure results. A network of interrelated controls — in the aggregate — constitutes a system of systems.

Casual attempts to understand an IC system's complexity and manage the interactions of the IC activities can lead to cognitive overload. The management challenge can feel so daunting that corporate executives may be reluctant to invest resources to sustain an effective IC program. Opportunities for transformative improvement are thus missed.

\section{The Proposed Solution}

A DSM-based validation tool ("the Validator" for short) can track the effectiveness of a system of IC activities. This decision-support tool assists in revealing likely limits on the effectiveness of specific activities - thereby highlighting opportunities to improve outcomes by adjusting the targeted application of resources. With the Validator, adjustments can be strategic, rather than hit-or-miss.

At least ten popular software packages are intended to assist in the documentation and management of IC activities (Aston 2021). However, it is not clear that any of the tools provide the effective holism needed to serve an entire enterprise IC system. Our proposed DSM solution offers a simple, low-cost, yet powerfully adaptive advantage - applying common spreadsheet software, tailored to the specific needs of an organization.

\section{Build the DSM}

Common spreadsheet software, such as Microsoft Excel, provides the platform for building the DSM. The rows, columns, and cells of the spreadsheet are the graphical starting point for creating a customized Dependency Structure Matrix (DSM) per Eppinger and Browning (2012). (Systems engineers may refer to a DSM as an " $N^{2}$ diagram.")

\subsection{Recognize the Complexity}

Identify and categorize the various activities deemed important for an IC program, tailored to suit your organization. For guidance on categorization, consult a professionally-vetted body of knowledge such as:

COSO 2013a. Internal Control - Integrated Framework. Five Components; 17 Principles. "Principles-based guidance for designing and implementing effective internal controls." "The most widely used internal control framework in the U.S." 
Denise Hunter, Carl Dister, Bill Klinger, Tyson Browning

INCOSE 2015. The INCOSE Systems Engineering Handbook describes 32 System Life Cycle Processes covering the definition, validation, design, integration, verification, manufacture, use, support, and retirement of engineered products (or services).

Built into both models is the notion of interconnectedness-essential for understanding and effectively managing the complex sociotechnical systems these models were developed to represent.

By conducting an extensive survey of businesses, Rae et al. (2017) examined interconnectedness in the COSO model. Their findings support a tenet of the COSO Integrated Framework: the COSO Components are not just standalone objects; rather, they influence one another. While this awareness is valuable, it would be helpful to have more than just a set of statistical correlations. DSMs offer the advantage of a concise, graphical representation of the interactions among the elements of a system.

\subsection{COSO DSM}

The COSO DSM (Figure 1) indicates the relative connectedness (or impact) of the relationships among the 17 COSO Principles (the IC Activities). To "read" the DSM, choose any IC Activity listed among the abbreviations heading the columns. View that activity as a potential informer or driver to each of the other activities (listed in the rows). Scan down the column to find intersectional cell values giving the relative impacts of the chosen activity.

\begin{tabular}{|c|c|c|c|c|c|c|c|c|c|c|c|c|c|c|c|c|c|c|}
\hline & EC & CG & EDM & cc & $C A$ & DO & RSKI & FAD & $\mathrm{cm}$ & DRMC & DTC & IC & VVI & сомı & COME & MONC & CIC & \\
\hline EC & 0 & 3 & 3 & 3 & 9 & 9 & 9 & 3 & 3 & 9 & 9 & 3 & 3 & 9 & 3 & 9 & 3 & \\
\hline$C G$ & 3 & 0 & 9 & 3 & 9 & 9 & 3 & 3 & 9 & 9 & 3 & 3 & 9 & 9 & 3 & 9 & 3 & $\begin{array}{l}\text { 喜 } \\
\text { on }\end{array}$ \\
\hline EDM & 9 & 9 & 0 & 9 & 3 & 9 & 9 & 3 & 3 & 9 & 9 & 3 & 3 & 3 & 3 & 9 & 0 & 孞. \\
\hline cc & 3 & 3 & 9 & 0 & 3 & 9 & 3 & 3 & 3 & 9 & 3 & 3 & 9 & 3 & 3 & 3 & 0 & \\
\hline CA & 9 & 9 & 3 & 3 & 0 & 3 & 3 & 3 & 3 & 9 & 3 & 3 & 3 & 9 & 3 & 9 & 0 & \\
\hline DO & 9 & 3 & 3 & 3 & 3 & 0 & 1 & 1 & 3 & 9 & 9 & 9 & 9 & 9 & 1 & 3 & 1 & \\
\hline RSKI & 3 & 9 & 3 & 3 & 9 & 9 & 0 & 3 & 3 & 1 & 1 & 1 & 3 & 9 & 1 & 1 & 1 & \\
\hline FAD & 9 & 3 & 3 & 3 & 3 & 3 & 9 & 0 & 3 & 1 & 1 & 1 & 1 & 3 & 1 & 9 & 1 & \\
\hline $\mathrm{cm}$ & 3 & 1 & 3 & 1 & 3 & 9 & 3 & 3 & 0 & 9 & 9 & 3 & 3 & 3 & 1 & 9 & 1 & \\
\hline DRMC & 9 & 3 & 3 & 1 & 9 & 9 & 9 & 3 & 3 & 0 & 1 & 9 & 9 & 1 & 1 & 9 & 3 & \\
\hline DTC & 1 & 1 & 3 & 0 & 0 & 1 & 1 & 1 & 3 & 1 & 0 & 9 & 9 & 1 & 1 & 9 & 1 & 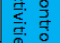 \\
\hline IC & 3 & 1 & 3 & 3 & 3 & 9 & 1 & 1 & 3 & 1 & 9 & 0 & 1 & 1 & 1 & 9 & 3 & \\
\hline al & 3 & 3 & 3 & 1 & 3 & 9 & 1 & 1 & 3 & 9 & 1 & 1 & 0 & 9 & 3 & 9 & 3 & 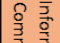 \\
\hline сомІ & 9 & 3 & 3 & 3 & 3 & 9 & 3 & 1 & 9 & 9 & 1 & 1 & 9 & 0 & 3 & 9 & 3 & \\
\hline СОMЕ & 3 & 3 & 3 & 1 & 3 & 3 & 1 & 1 & 9 & 9 & 1 & 1 & 9 & 9 & 0 & 1 & 0 & 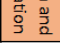 \\
\hline MONC & 9 & 9 & 3 & 1 & 3 & 9 & 3 & 3 & 3 & 3 & 3 & 9 & 9 & 3 & 3 & 0 & 1 & 索竞 \\
\hline CIC & 3 & 3 & 3 & 3 & 3 & 3 & 3 & 3 & 3 & 9 & 9 & 9 & 3 & 3 & 3 & 1 & 0 & 营高 \\
\hline
\end{tabular}

Figure 1. COSO DSM (The abbreviations are expanded in the Principle column of Table 1.) 
The objective of the Validator is to reveal likely limits on the effectiveness of specific processes operating in a system - in this case, a system of IC Activities. We build our method upon the COSO DSM's tracking of dependencies and interactions between any given activity and each of the other activities. Consider that the outputs of some activities serve as inputs to other activities. If the quality (accuracy or validity) of a given output is poor, then the effectiveness of the dependent activity is reduced. In the next section, we determine "By how much?"

\subsection{Set Up the Validation Calculator}

To generate a guiding figure-of-merit - namely, the Maximum PAC Level - the Validation Calculator operates on values contained in cells of the COSO DSM, together with values in the COSO Validator. First, the Excel SUMPRODUCT function returns the sum of the products of the COSO DSM's cell values (the weights, taken column by column) and the COSO Validator's PAC Level column entries. Next, the SUMPRODUCT results are divided by the SUM of the COSO DSM's cell values (taken column by column).

To observe the Validator calculation process for just one of the 17 COSO Principles, look first at the COSO DSM (Figure 1). As an example, let us focus on the Ethical Commitment Principle, represented by the EC abbreviation in the upper-left corner of the matrix. The first column, headed EC, contains the 0-1-3-9 weights that indicate the relative connectedness of EC to the other 16 COSO Principles. Each of the 17 EC Weights is a factor (the multiplier) in the series of multiplications in Equation 1, below. Now, look at the COSO Validator (Table 1). Each "score" in the PAC Level column is a factor (the multiplicand) in the series of multiplications. In Equation 1, the 17 products are summed, then divided by the sum of the 17 EC Weights.

Maximum PAC Level $=(0)(0.95)+(3)(0.30)+(9)(0.95)+(3)(0.50)+(9)(0.05)+$ $(9)(0.50)+(3)(0.05)+(9)(0.50)+(3)(0.50)+(9)(0.95)+(1)(0.95)+(3)(0.50)$ $+(3)(0.30)+(9)(0.30)+(3)(0.95)+(9)(0.05)+(3)(0.95) /(0+3+9+3+9+$ $9+3+9+3+9+1+3+3+9+3+9+3)=42.8 / 88.0=0.49$ [rounded to two significant figures] (1)

Bottom-Line Observation: The Fortune 100 company executives assumed the Ethical Commitment PAC Level score to be 0.95 , but the Validator reports a Maximum PAC Level of merely 0.49. Resulting Capability Level Assessment: Implausible.

\subsection{How the Validation Calculator Works}

Imagine the PAC Levels in the COSO Validator to be physical "masses" and the connection strengths in the COSO DSM to be "distances" along a lever, relative to the fulcrum. The calculation of a Maximum PAC Level, in essence, applies Archimedes' center of gravity equation (Heath 1897) to determine what the maximum value should be to balance the entire system. The center of gravity equation is applied by establishing the fulcrum point to self-adjust to the natural center of the system, "discovering" what the optimum connection strengths in the COSO DSM should be to achieve desired objectives, which are the Maximum PAC Levels. For example, if the PAC values are presumed to be higher than a balanced system would suggest, results should be more closely examined. Recognizing that the connection strengths are all interconnected helps one to appreciate the criticality of placing just the right connection strength at the correct distance, to maintain the natural balance point, thereby increasing the connection strengths closer to 
the PAC value. Note that the center of gravity calculation (Equation 2) consists of a sum of products divided by a sum, just like the Validation Calculator:

Center of Gravity $=\frac{\sum_{i=1}^{n} \text { Mass }_{i} \times \text { Distance }_{i}}{\sum_{i=1}^{n} \text { Mass }_{i}}$

We considered alternative approaches (Newman 2018) for the centrality calculation, including PageRank, degree centrality, Katz centrality, and eigenvector centrality (the last option being most similar to the center of gravity calculation). Since the COSO Activities lack any inherent "physical constants" relating them, there is no need for artificial weights. Therefore, eigenvector centrality (which uses no weights) was our favored choice. However, we settled on the center of gravity because it seems to be an easier concept for most people to grasp.

\subsection{Sensitivity Analysis}

We performed a sensitivity analysis of the Validator, examining "the extent to which each individual source of uncertainty contributes to the output variance" (ISO/IEC 33003, Section 4.7.2). In our what-if analysis, we randomly varied the value of each PAC Level by $\pm 5 \%$. We ranked the resulting Maximum PAC Levels from 1 to 17, covering the 17 IC Activities. We ran the what-if analysis in Excel for 1,000 trials. The outcome confirmed the relatively stable behavior of the Validator: the Maximum PAC Levels shifted up or down by just 1 to 3 positions (out of 17) over the $\pm 5 \%$ PAC Level range.

Over the past five years, the authors have used the Validator to check the coherence of expert-opinion scoring of ICs. In cases with multiple implausible Capability Level Assessment scores (more than $20 \%$ of all scores), the Internal Controls Evaluation Teams request additional evidence and perform further interviews, to improve the scores. Those teams report that the Validator reveals areas they may have rushed through or failed to evaluate carefully. Our real-world applications have tested and proven the tool's effectiveness - albeit in a rather limited set of experiments to date.

\section{Use the Validator}

\subsection{Good Practices from Systems Thinking}

The utility of the Validator rests on three informed practices:

Build on Known Scenarios. Instead of reinventing the wheel for each new set of ICs, tailor a familiar set of comparable interconnections to represent the new case-thereby speeding the process.

Learn from the Interconnectedness. Analyze the inherent interconnections, dependencies, and impacts in the IC system, to build a foundation for evidence-based decision making.

Appreciate the Dynamic Environment. The IC activities tracked by the Validator are not fixed, static processes; they naturally shift and evolve. Perceiving the interconnections as vectors - pointing somewhere at the moment, yet continuously on the move-respects the complex dynamics that ripple through all organizations and their endeavors. 


\subsection{An Auditor's Procedure for Using the Validator}

To assess a given IC system, an auditor first enters PAC Level values into the COSO Validator, according to the numerical ranges defined in (ISO/IEC 33020, Section 5.3). Based on the interconnectedness of the underlying COSO DSM, the COSO Validator calculates Maximum PAC Levels. When the inputs to an assessed Principle exhibit a centered fit within the coherent whole, the Capability Level Assessment reports Good. A Non-Optimized assessment suggests an opportunity for process improvement. An assessment of Implausible is a red-flag warning of deficient ICs (or poor assessment by the auditor). These indicators supply systemic insights that prompt the auditor to target action for a better risk-opportunity balance.

\subsection{Applying the Validator to the Real-World Case}

In the first author's story, corporate executives remained oblivious to deceptive activities until the expert audit team began to probe. The company had long assumed a Fully Achieved (F) Process Attribute Rating for COSO's Ethical Commitment Principle. Unfortunately, management's "cosmetic" controls were, in fact, much less achieved than presumed. The weak controls proved inadequate to prevent fraud, when confronted by multiple instances of human failure to comply.

The shortcomings of the cosmetic controls can be discerned in multiple rows of the "original" COSO Validator (Table 1). For instance, the executives believed the Ethical Commitment PAC Level to be 0.95 . Had the Validator been available to the company, the tool would have provided the smoking gun: A Capability Level Assessment of Implausible for the Ethical Commitment Principle, based on a Maximum PAC Level of 0.49 .

After discovering the employee misconduct, the firm invested some $\$ 325,000$ to improve Controls Accountability and Internal Communication. Assume that those two targeted interventions increased the related PAC Level scores to 0.90, as shown in Table 2. The Validator indicates that those interventions alone would not bring Ethical Commitment to the originally assumed 0.95 score, but could raise it to 0.63 - a $29 \%$ improvement on the original 0.49 limit. We see management's intervention effort as a pragmatic balancing of opportunity and risk. Management could have used the Validator to further optimize Ethical Commitment by adjusting combinations of other principles to yield a value greater than 0.63 .

\section{Conclusions}

In our real-world case, internal control deficiencies allowed deceptive, unethical behavior to go undetected for years. A conscientious application of the Validator could have timely alerted the Fortune 100 company to the need to adjust their application of resources, optimizing the effectiveness of the corporate internal control system. More broadly, the Validator can aid auditors in assuring that the cost of controls does not exceed the benefits. 


\begin{tabular}{|c|c|c|c|c|c|c|c|}
\hline Component & Principle & $\begin{array}{c}\text { Process } \\
\text { Attribute } \\
\text { Capabiliy } \\
\text { Level }\end{array}$ & $\begin{array}{l}\text { Process } \\
\text { Attribute } \\
\text { Rating }\end{array}$ & $\begin{array}{c}\text { Maximum } \\
\text { Process } \\
\text { Attribute } \\
\text { Capability } \\
\text { Level }\end{array}$ & $\begin{array}{c}\text { Maximum } \\
\text { Process } \\
\text { Attribute } \\
\text { Rating }\end{array}$ & $\begin{array}{l}\text { Capability } \\
\text { Level } \\
\text { Validation } \\
\text { Ratio }\end{array}$ & $\begin{array}{l}\text { Capability Level } \\
\text { Assessment }\end{array}$ \\
\hline \multirow{5}{*}{$\begin{array}{l}\text { Control } \\
\text { Environment }\end{array}$} & Ethical Commitment (EC) & 0.95 & $\mathrm{~F}$ & 0.63 & $\mathrm{P}$ & 1.5 & IMPLAUSIBLE \\
\hline & Controls Governance (CG) & 0.30 & $\mathrm{P}$ & 0.59 & $\mathrm{P}$ & 0.5 & NON-OPTIMIZED \\
\hline & Established Decision Making (EDM) & 0.95 & $\mathrm{~F}$ & 0.57 & $\mathrm{P}$ & 1.7 & IMPLAUSIBLE \\
\hline & Commitment to Competence (CC) & 0.50 & $\mathrm{P}$ & 0.68 & $\mathrm{P}$ & 0.7 & NON-OPTIMIZED \\
\hline & Controls Accountability (CA) & 0.90 & $\mathrm{~F}$ & 0.58 & $\mathrm{P}$ & 1.6 & IMPLAUSIBLE \\
\hline \multirow{4}{*}{ Risk Assessment } & Defined Objectives (DO) & 0.50 & $\mathrm{P}$ & 0.58 & $\mathrm{P}$ & 0.9 & NON-OPTIMIZED \\
\hline & Risk Identification and Ranking (RSKI) & 0.05 & $\mathrm{~N}$ & 0.74 & $\mathrm{~L}$ & 0.1 & NON-OPTIMIZED \\
\hline & Fraud Analysis and Detection (FAD) & 0.50 & $\mathrm{P}$ & 0.62 & $\mathrm{P}$ & 0.8 & NON-OPTIMIZED \\
\hline & Change Management (CM) & 0.50 & $\mathrm{P}$ & 0.66 & $\mathrm{P}$ & 0.8 & NON-OPTIMIZED \\
\hline \multirow{3}{*}{ Control Activities } & Define Risk Mitigation Controls (DRMC) & 0.95 & $\mathrm{~F}$ & 0.67 & $\mathrm{P}$ & 1.4 & IMPLAUSIBLE \\
\hline & Define Technology Controls (DTC) & 0.95 & $\mathrm{~F}$ & 0.67 & $\mathrm{P}$ & 1.4 & IMPLAUSIBLE \\
\hline & Implement Controls (IC) & 0.50 & $\mathrm{P}$ & 0.67 & $\mathrm{P}$ & 0.7 & NON-OPTIMIZED \\
\hline \multirow{3}{*}{$\begin{array}{l}\text { Information and } \\
\text { Communication }\end{array}$} & Quality Information (QI) & 0.30 & $\mathrm{P}$ & 0.65 & $\mathrm{P}$ & 0.5 & NON-OPTIMIZED \\
\hline & Communication - Internal (COMI) & 0.90 & $\mathrm{~F}$ & 0.58 & $\mathrm{P}$ & 1.6 & IMPLAUSIBLE \\
\hline & Communication - External (COME) & 0.95 & $\mathrm{~F}$ & 0.63 & $\mathrm{P}$ & 1.5 & IMPLAUSIBLE \\
\hline \multirow{2}{*}{$\begin{array}{l}\text { Monitoring } \\
\text { Activities }\end{array}$} & Monitor Controls (MONC) & 0.05 & $\mathrm{~N}$ & 0.69 & $\mathrm{P}$ & 0.1 & NON-OPTIMIZED \\
\hline & Continuously Improve Controls (CIC) & 0.95 & $\mathrm{~F}$ & 0.59 & $\mathrm{P}$ & 1.6 & IMPLAUSIBLE \\
\hline
\end{tabular}

Table 2. COSO Validator showing the effects of two interventions.

We reference the COSO and INCOSE frameworks as examples of two expertlyestablished, systemic life-cycle controls. Fortunately, the fundamental control concepts are broadly portable to any organization or endeavor seeking a holistic assessment of operations.

We encourage readers to build a DSM representing any suitable, coherent set of processes for the mission of interest, then apply the Validator to gain insight toward improvement. View your DSM and the Validator as living documents. Environmental and organizational dynamics call for periodic refreshes of the Capability Levels. Be alert for changing conditions that might upset the system's balance.

The interpretation of human-behavior phenomena, such as ICs, is typically subjective-far afield from a physics-based set of equations. So far, our method does not accommodate negative weights nor alternative centrality measures. However, the simplicity of the center of gravity approach and our implementation via a basic spreadsheet has provided a tool of considerable utility to audit teams - one that may be extended with further research and development.

\section{References}

Aston, Ben. 2021. "The 10 Best GRC Tools (Government, Risk, Compliance) in 2021." (webpage published January 27, 2021) The Digital Project Manager (dpm) (website) https://thedigitalprojectmanager.com/grc-tools/\#reviews

Committee of Sponsoring Organizations of the Treadway Commission (COSO). 2013a. Internal Control - Integrated Framework. Durham, NC: American Institute of Certified Public Accountants (AICPA).

Committee of Sponsoring Organizations of the Treadway Commission (COSO). 2013b. Internal Control - Integrated Framework - Executive Summary. Durham, NC: American Institute of Certified Public Accountants (AICPA). 
Eppinger, Steven D., and Tyson R. Browning. 2012. Design Structure Matrix Methods and Applications. Cambridge, MA: MIT Press.

Heath, Thomas Little. 1897. The Works of Archimedes: Edited in Modern Notation with Introductory Chapters. Cambridge, England: Cambridge University Press.

International Council on Systems Engineering (INCOSE). 2015. Systems Engineering Handbook: A Guide for System Life Cycle Processes and Activities. 4th Ed. Hoboken, NJ: John Wiley \& Sons, Inc.

ISO/IEC 33003:2015, Information Technology - Process Assessment - Requirements for Process Measurement Frameworks. First edition, 2015-03. Geneva, Switzerland: International Organization for Standardization.

ISO/IEC 33020:2019, Information Technology - Process Assessment - Process Measurement Framework for Assessment of Process Capability. Second edition, 2019-11. Geneva, Switzerland: International Organization for Standardization.

Jackson, Michael C. 2019. Critical Systems Thinking and the Management of Complexity. Hoboken, NJ: John Wiley \& Sons, Inc.

Maier, Anja M., James Moultrie, and P. John Clarkson. 2011. "Assessing Organizational Capabilities: Reviewing and Guiding the Development of Maturity Grids." IEEE Transactions on Engineering Management Volume 59, Number 1, pp. 138-159.

Newman, Mark. 2018. Networks. Second Edition, Oxford University Press.

Rae, Kirsten; John Sands; and Nava Subramaniam. 2017. "Associations among the Five Components within COSO Internal Control-Integrated Framework as the Underpinning of Quality Corporate Governance," Australasian Accounting, Business and Finance Journal, Volume 11, Number 1, pp. 28-54. 